\title{
Florecimiento de algas nocivas (FANs), ecosistemas marinos y la salud humana en la Patagonia chilena*
}

\author{
Felipe C. Cabello y Henry P. Godfrey
}

\author{
Harmful algal blooms (HABs), marine ecosystems and human health \\ in the Chilean Patagonia
}

\section{L}

a Región de Los Lagos en la Patagonia Chilena está localizada entre las latitudes $40^{\circ} 13^{\prime}-44^{\circ} 30^{\prime}$ S y las longitudes $74^{\circ} 49^{\prime}-71^{\circ} 34^{\prime}$ W. Esta región comprende un gran ecosistema marino entre el Océano Pacifico y la Cordillera de Los Andes y contiene dos mares interiores. El mar interior de la isla grande de Chiloé y el Golfo del Reloncaví y múltiples archipiélagos, estuarios y fiordos. Las características geográficas de la región con sus innumerables bahías, canales, islas y fiordos y la gran biodiversidad de la flora y fauna del mar han servido desde muchos años como estímulo al desarrollo de una gran industria pesquera y acuícola, incluyendo esta última salmonideos y mitilidos. Esta región produce alrededor de $50 \%$ del salmón exportado por Chile, país que después de Noruega, es el segundo productor de este alimento con alrededor de 800.000 toneladas anuales. Los Lagos también produce $80-90 \%$ del pescado, el marisco y las algas consumidas en el país y exportadas e, indudablemente, el área representa para Chile un relevante asiento industrial basado en la explotación del ecosistema marino y sus recursos.

Este año el ecosistema marino de Los Lagos ha experimentado una serie de fenómenos biológicos que tienen el potencial de quebrantar su vibrante economía, afectando negativamente en el futuro a la salmonicultura, el cultivo de mitilidos y similarmente la pesca ${ }^{1,2,3}$. En enero y en febrero de 2016 la salmonicultura, en la parte norte del mar interior de Chiloé, el Golfo de Reloncaví y el estuario del mismo nombre, experimentó una masiva mortandad de salmones producida por un FAN con el alga Pseudochattonella marina ${ }^{1}$. Este FAN eliminó a aproximadamente 50. 000 toneladas de salmones y le produjo a la industria importantes pérdidas económicas que además se acompañaron de importante desempleo ${ }^{1,2}$. En abril y mayo, un FAN de Alexandrium catenella, una alga que produce una neurotoxina paralítica que afecta a humanos, se extendió rápidamente desde la parte sur del mar interior de Chiloé hacia el norte, cubriéndolo casi en su totalidad, y proyectándose hacia el Golfo de Reloncaví y hacia el norte. Inesperadamente, luego este FAN se expandió hacia el mar abierto en el Océano Pacifico extendiéndose 300 a $400 \mathrm{~km}$ hacia el norte de la
Isla Grande de Chiloé ${ }^{3}$ En el Océano Pacifico este FAN fue acompañado de mortalidades masivas de moluscos y de pájaros marinos. Como resultado de este FAN, el gobierno prohibió la pesca y el consumo de mariscos silvestres y cultivados contaminados con toxina paralítica, creando más desempleo y problemas económicos y de alimentación para importantes grupos de la población. Esto obligó al gobierno a declarar un estado de emergencia en el área e instaurar una política de subsidios para los desempleados y sus familias.

La Región de Los Lagos ha experimentado FANs en el pasado reciente ${ }^{4-7}$; sin embargo, la extensión, la intensidad y los niveles de toxicidad de estos últimos FANs aparecen como inusitados, impartiéndoles a ellos características biológicas no vistas hasta ahora en la zona $^{1-3}$. Como los FANs, una vez que aparecen en un área tienen la tendencia a repetirse, su potencial reaparición en el área de Los Lagos plantea dudas acerca del futuro de las dos importantes actividades económicas en la región, la pesca y la acuicultura y el bienestar económico y la gobernabilidad del área. En el ecosistema marino en esta región también se encuentran algas con toxinas diarreicas y otras que producen amnesia, las cuales también podrían dar origen a FANs en el futuro, agravando aún más la situación ${ }^{6}$. Además la región también ha experimentado en el pasado epidemias de diarrea por Vibrio parahaemolyticus que pudieran volver a repetirse y una serie de nuevo patógenos bacterianos y virales de peces han aparecido también en la zona afectando negativamente a la acuicultura $^{6}$. Recientemente el mar de Los Lagos ha visto florecimientos de fragatas portuguesas que igualmente afectan negativamente a la pesca y a la recreación y el área también ha experimentado inusitadas mortandades de ballenas.

En resumen, pareciera que estos hechos indican que el extenso ecosistema marino de la Región de Los Lagos y regiones aledañas está sufriendo una importante inestabilidad y degradación ecológica. El cambio climático con un fenómeno de El Niño intenso y el aumento de las temperaturas del mar han sido inculpados por estos fenómenos. Sin embargo, en la región además existen otros desafíos que juegan un papel importante en estos
New York Medical College, Valhalla, New York, U.S.A. Department of Microbiology and Immunology (FCC). Department of Pathology (HPG).

*Una versión previa de este texto fue publicada en ingles el 5 de agosto de 2016, en ProMED-mail, el Programa Para Monitorear Enfermedades Emergentes de la International Society for Infectious Diseases, Boston, Mass. U.S.A.

Recibido: 2 de septiembre de 2016 Aceptado: 22 de septiembre de 2016

Correspondencia a:

Felipe Cabello cabello@nymc.edu 
procesos como son el exceso de nutrientes o eutrofización en el mar generado por la acuicultura del salmón y de mitilidos, la pesca excesiva y el uso permanente en estos ambientes de antimicrobianos, antiparasitarios y una variedad de substancias químicas usadas para prevenir y tratar enfermedades y evitar la incrustación de estructuras industriales por flora y fauna ${ }^{4-8}$. La acuicultura y la pesca han generado también importantes pérdidas de hábitats y disminuciones de la biodiversidad mediadas por ejemplo por el escape de salmones y la pesca excesiva de algunas especies que linda en su desaparición. La suma de estos procesos de degradación ambiental atentan contra la capacidad de equilibrio del ecosistema marino antes diversos desafíos y socavan su habilidad para prestar servicios como fuente sana de alimentos y en la recreación.

Pareciera ser que, como resultado de estos problemas, la Región de Los Lagos y la Patagonia chilena atraviesan por un proceso de degradación antropogénica de los ecosistemas marinos que con un trasfondo de calentamiento global está generando una serie de problemas ecológicos que aumenta aún más su degradación ${ }^{9-12}$. Estas interacciones dinámicas están generando la aparición de enfermedades que afectando la flora y fauna en el mar y que tienen además el potencial de afectar negativamente la salud humana y las importantes actividades económicas de la región. Desarrollos de este tipo, en los cuales la degradación de ecosistemas marinos y su vulnerabilidad ecológica se acompañan de procesos negativos para la salud humana y las actividades económicas fueron visionariamente e intelectualmente concebidos y previstos en varias publicaciones hace más de 20 años atrás por el Grupo de Enfermedades Emergentes de la T. H. Chang Escuela de Salud Pública de la Universidad de Harvard $^{9-12}$. Este grupo hizo también un llamado para el estudio holístico e integrado de estos problemas que estimaron necesario para predecir y prevenir la aparición de ellos y evitar sus impactos negativos sobre la sociedad. Los fenómenos descritos sumariamente aquí indicarían que ha llegado el tiempo para escuchar y reflexionar en Chile sobre este llamado con cierta urgencia para prevenir mayores problemas ecológicos con un potencial negativo para la salud pública.

Agradecimientos. Agradecemos a Don Patricio Melillanca la información respecto de las resoluciones del Servicio Regional Ministerial de Salud de Los Lagos prohibiendo el consumo humano de mariscos contaminados con toxinas de marea roja.

\section{Referencias bibliográficas}

1.- ProMED-Mail. Published Date: 201604-13 16:57:09Subject: PRO/AH/EDR> Red tide - Chile: salmon Archive Number: 20160413.4157718.

2.- Clement A, Lincoqueo L, Saldivia $M$, Brito C G, Muñoz F, Perez F, y cols. Exceptional summer conditions and HABs of Pseudochatonella in Southern Chile create record impacts on salmon farms. Harmful Algae News 2016. No 53 May 1-3

3.- ProMED-Mail. Published Date: 2016-0513 10:53:23 Subject: PRO/AH/EDR> Red tide-Chile (02): salmon Archive Number: 20160513.4219113.

4.- Buschmann A. Marea roja y salmonicultura en el Sur de Chile. 2005. Oceana. Santiago. Chile.

5.- Buschmann $\mathrm{A} \mathrm{H}$, Riquelme V A,
Hernández-González M C, Varela D, Jiménez J E, Henríquez L A, et al. A review of the impacts of salmonid farming on marine coastal ecosystems in the southeast Pacific. 2006. ICES J Mar Sci 2006; 63 (7): 1338-45.

6.- Hernández C, Ulloa J, Vergara JA, Espejo R, Cabello F. Infecciones por Vibrio parahaemolitico e intoxicaciones por algas: problemas emergentes de salud pública en Chile. Rev Med Chile 2005; 133 (9): 1081-8. Epub 2005 Nov 9. PubMed PMID: 16311702.

7.- Cabello F. Enfermedades originadas en el mar. ¿Síntomas del deterioro de la biodiversidad marina en la Décima Región? Ambiente y Desarrollo 2005; 20/21: 80-7.

8.- Cabello F C. Heavy use of prophylactic antibiotics in aquaculture: a growing problem for human and animal health and for the environment. Environ Microbiol 2006; 8 (7):
1137-44. Review. PubMed PMID: 16817922.

9.- Epstein P R. Emerging diseases and ecosystem instability: new threats to public health. Am J Public Health 1995; 85 (2): 168-72. Review. PubMed PMID: 7856775; PubMed Central PMCID: PMC1615306.

10.- Epstein P R, Ford T E, Colwell R R. Marine ecosystems. Lancet 1993; 342 (8881): 1216-9. PubMed PMID: 7901535.

11.- Epstein P R, Ford T E, Puccia C, Possas C A. Marine ecosystem health. Implications for public health. Ann N Y Acad Sci 1994; 740: 13-23. Review. PubMed PMID: 7840444.

12.- Harvell C D, Kim K, Burkholder J M, Colwell R R, Epstein P R, Grimes D J, et al. Emerging marine diseases-climate links and anthropogenic factors. Science 1999; 285 (5433): 1505-10. Review. PubMed PMID: 10498537. 